\title{
Optimality Theory with Lexical Selection needs multiple PRIORITIES: A case study in Welsh allomorphy
}

\author{
Mykel Loren Brinkerhoff*
}

\begin{abstract}
This study illustrates the role of Lexical Selection (Mascaró 2007) in Optimality Theory in accounting for the Welsh definite article's allomorphy. This is in response to the claims made by Hannahs \& Tallerman (2006) that OT is unable to account for the behavior and distribution of the definite article. This study addresses three of the points that Hannahs \& Tallerman raised which I am calling the grammar problem, the homophony problem, and the allomorph interaction. I show that Lexical Selection is uniquely adapted to account for each of the points concerning the definite article allomorphy. Additionally, this study proposes that Lexical Selection needs to be amended with multiple Priority constraints that are morpheme specific. It also appears that there appears to exist a unique relationship between the constraint rankings of these multiple Priority constraints in what is called the prioritization of the hierarchy.
\end{abstract}

Keywords. OT/LS; prioritization; Lexical Selection; Welsh; allomorphy

1. Introduction. The purpose of this study is to illustrate the strength of Optimality Theory (Prince \& Smolensky 2004) in handling cases of allomorphic variation. One such case involves the allomorphy of the definite article in Welsh which has three distinct allomorphs. This study addresses this as well as addresses the claims made by Hannahs \& Tallerman (2006) (hereafter referred to as H\&T) as to the inability of OT to handle cases of allomorphy in Welsh.

The apparent concerns with OT's inability to handle Welsh allomorphy are resolved with the introduction of Lexical Selection (LS; Bonet, Lloret \& Mascaró 2007; Mascaró 2007; Mascaró 2008; McCarvel 2016) into the general theory of constraint-based grammars (abbreviated as OT/LS). Lexical Selection is ideally situated to handle cases involving the interaction of morphology and phonology, especially in cases of phonologically conditioned allomorphy (PCA) and exceptional allomorphy. The theory accomplishes this by restricting the role that morphology is allowed to interact with the rest of the grammar to a bare minimum allowing allomorph sets for each morpheme as well as the introduction of a constraint PRIORITY to allow for the prioritization of one allomorph over the others within a set (see section 4 for more information).

The strength of this study lies in limiting the role that morphology plays. By limiting the role of morphology, the phonological component of the analysis is allowed to play a more significant role in the determination of the correct form of the morpheme being allowed to surface. Additionally, this study will propose that LS needs to be augmented with the use of multiple PRIORITY constraints with each PRIORITY constraint corresponding to a specific morpheme. I additionally propose that there exists a specific constraint ranking between these multiple instances of Priority. This is what I call the Prioritization of the Hierarchy and occurs if one morpheme's final phonological shape determines the phonological shape of another morpheme then that first morpheme's corresponding PRIORITY constraint is ranked higher in the constraint hierarchy than the

\footnotetext{
* I would like to thank the feedback and support I received from Jennifer Smith, the UNC Linguistics Department, UNC P-side group for hearing previous versions of this research. I would also like to thank Sam Zukoff and Gareth Roberts for feedback and suggestion during the LSA about various points in this research. Finally, I want to especially thank the support of my wife Betsy. Author: Mykel Loren Brinkerhoff, University of North Carolina at Chapel Hill (mybrink@live.unc.edu).
} 
other morpheme's corresponding PRIORITY constraint (see section 5.3 for more discussion on this concept).

In order to show the strength of this proposal as a solution to Welsh allomorphy, particularly the definite article, and the Prioritization of the Hierarchy for some constraints the study will first proceed with an account of the data of the descriptive generalizations that characterize the definite article in Welsh and other cases of Welsh phonologically conditioned allomorphy in section 2. Section 3 is devoted to the review of H\&T and the claims that they raised therein. Section 4 is an overview of the theory of Lexical Selection. Section 5 will present an analysis of the Welsh allomorphy. Section 6 will be the conclusion.

2. Data and descriptive generalizations. The definite article in Welsh has three distinct allomorphic forms $(y / y r / ' r)$, which are all phonologically determined. The allomorph $y$ appears when the following word begins with a consonant, while the $y r$ allomorph's phonological conditioning is when the following word begins with a vowel, glide, or the phone [h] (H\&T:782). The third allomorph of the definite article ' $r$ (called in the literature the enclitic form, see H\&T and their references for more on this) takes precedence over those of the other allomorphs whenever the preceding word is vowel-final regardless of the following context. This generalization is summarized below in (1). All examples in this paper are from H\&T unless otherwise indicated.

(1) Welsh definite article by environment with examples. ${ }^{1}$

$y r / \mathrm{V}, \mathrm{h}, \mathrm{g}$

yr afon'the river

$$
\begin{aligned}
& y / \mathrm{C} \\
& y \overline{l l} y f r \text { 'the book' }
\end{aligned}
$$

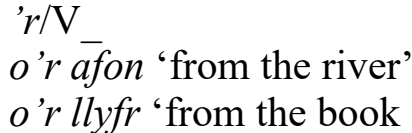

$o$ 'r llyfr 'from the book

Based on the generalizations described in the preceding paragraph and in (1), the behavior appears to be a simple case of phonologically conditioned allomorphy (PCA). However, this is not the case because the ' $r$ allomorph taking precedence over the other allomorphs when its environment is present.

(1) The precedence of ' $r$
a. o'r llyfr $/ *$ o y llyfr $\quad$ (Preposition)
from-the book
'from the book'
b. Brynaist ti'r llyfr?/* Brynaist ti $\boldsymbol{y}$ llyfr (Determiner) buy-PST-2SG you-the book
'Did you buy the book?'
c. Pwy ydy'r
Who be- PRES-IND-3SG-the doctor
meddyg?/* Pwy ydy y meddyg?
'Who is the doctor?'
d. rhieni'r ysgolfeister/* rhieni yr ysgolfeister (Noun) parents-the schoolmaster 'the parents of the schoolmaster?'

As explained by H\&T (784), this ' $r$ allomorph has another property that makes it unprecedented and is an argument against the allomorphy of the definite article being a simple case of PCA. This is due to this allomorph occurring in environments that it would otherwise seem best to avoid.

\footnotetext{
${ }^{1}$ Welsh examples and inputs are left in their orthographic forms because of a lack of a standardized pronunciation for Welsh. IPA transcriptions will be used where needed for clarification.
} 
In Welsh, there is a small class of morphemes that alternate between a vowel-final form and a consonant-final form, see (3). The consonant-final form of these morphemes surfaces only when the following word is vowel-initial, in all other cases the vowel-final form is observed.

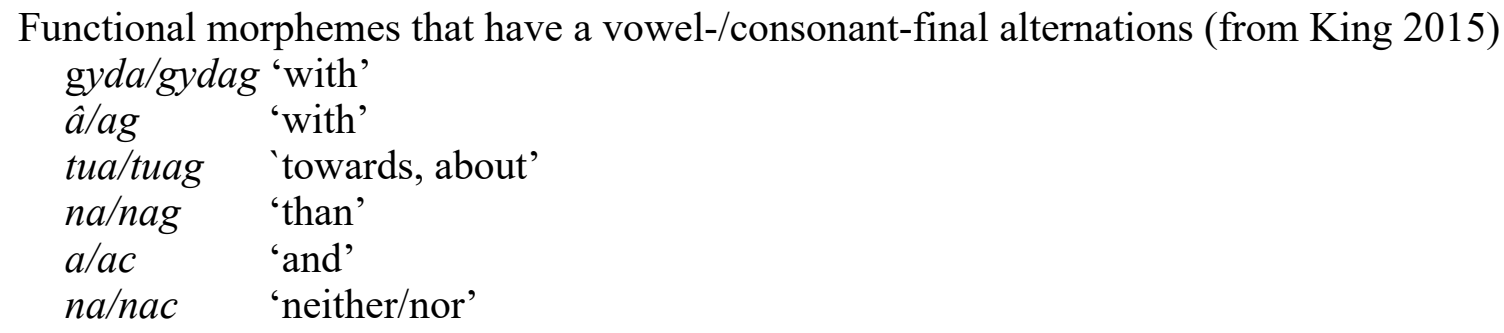

When these morphemes appear before the definite article, the expected form would be the consonant-final form of the morphemes in (3). This is because of the resulting syllable structure that this would produce. This expected syllable structure, however, is not what we observe in the data. What we do observe is the vowel-final form with the ' $r$ form of the definite article. This observed form, (4a), has one NoCODA violation more than that of the expected form in (4b).

(3) The interaction of gyda and the definite article before a C-initial word

a. Observed form has two NoCODA violations gyda'r nod [ gi.dar.nod ]

'with the aim'

b. Expected form has one NoCODA violation

* gydag y nod [ gi.da.gə.nod ]

'with the aim

Because of this behavior, it would seem preferable that the consonant-final form of the morphemes in (3) be the ones that are present in the data.

3. Hannahs and Tallerman (2006). H\&T explore the selection of the definite article in Welsh and claim that the distribution of the definite article is evidence for late insertion functional morphemes and that lexical insertion occurs in a staggered fashion in keeping with the theoretical framework of Distributed Morphology (Halle \& Marantz 1993). This means that content words are inserted first followed by the insertion of function morphemes (e.g., propositions and articles) during the derivation from syntax's DS to PF with the phonology coming into effect at each stage of insertion to apply various phonological changes to the inserted morphemes. Nevertheless, H\&T did evaluate the validity of using phonological frameworks for modeling and analyzing the patterning of not only the Welsh definite article but Welsh allomorphy generally, because many cases of phonologically conditioned allomorphy can easily be accounted for by using purely phonological means. Notwithstanding, they claim "that even if a purely phonological account were proposed, it could not constitute a perspicuous solution to the issues here, in light of the interplay of phonological, morphological and lexical factors which govern the selection of forms (H\&T:787)."

In their rejection of a phonological account, they claim that OT, if OT is understood to consist of a morpheme only having a single input and that syllabification does not occur as a result of EVAL, fails to be able to account for this on several points that I will call, and summarized below, the grammar problem, the homophony problem, and the allomorphy interaction problem.

The grammar problem arises from the fact that the definite article and other Welsh allomorphs appear to violate constraints on the phonological component of the grammar. These apparent violations are due to the use of the definite article and the other vowel-/consonant-final alternating morphemes appearing to purposely avoid instances of hiatus and codas in favor of 
lesser marked phonological structures, whereas the rest of the grammar does not avoid hiatus or codas H\&T (787).
Examples of hiatus and codas in Welsh
a. $P\left[\begin{array}{ll}\text { oi } & \text { o }\end{array}\right] d y^{\prime} r$
who be- PRES-IND-3SG-the
meddyg
'Who is the doctor.'
doctor (hiatus across word boundaries)
b. tua
towards
[ti.a]
'towards' (hiatus word-interanally)
c. llyfr
book
[li.vir]
'book' (coda word-finally)
d. Pwy [ə.dir]
who be- PRES-IND-3SG-the doctor
'Who is the doctor?' (coda phrase-internally and word-finally)

The introduction of LS into OT remedies this point as will be seen in section 5.

The next point that H\&T claim about OT's inability to account for Welsh allomorphy is the presence of a homophonous morpheme to the definite article. This homophonous morpheme is a preverbal particle whose behavior and allomorphic distribution is entirely distinct from that of the definite article. For the preverbal particle, the locus of the alternation is within the same complementizer phrase, which according to Selkirk (2009) is analogous to the prosodic intonational phrase. The allomorphs $y$ and $y r$ follow the same behavior as that of the definite article. The principal difference lies in the distribution of the ' $r$ allomorph. This allomorph is primarily present when it is intervocalic. ${ }^{2}$ According to H\&T (787), this fact "is fatal to any purely phonological account," because it should pattern exactly the same as the This point is what I term the homophony problem and as will be seen in section 5.2, LS remedies this point as well.

(6) Welsh definite article by environment with examples.

$y r l_{-} \mathrm{V} \quad y /{ }_{-} \mathrm{C} \quad r / \mathrm{V}_{-}$

(7) Examples of the preverbal particle $y / y r$.

a. Dywedodd. hi [ст $\boldsymbol{y}$ bydd cyngerdd heno]. say-PST-3SG. she PRT be-FUT-3SG concet tonight 'She said there will be a concert tonight.'

$\begin{array}{llllll}\text { b. Dw i'n } & \text { credu } & \text { [ст } \boldsymbol{y} \boldsymbol{r} & \text { hoffai } & \text { Eluned fynd] } \\ \text { be-1SG I-PROG } & \text { believe } & \text { PRT } & \text { like-COND-3SG } & \text { E. go }\end{array}$ 'I believe that Eluned would like to go.'
c. $\quad \boldsymbol{Y} \boldsymbol{r}$ oedd yn y fan [CP lle'r oedd Martha wedi ei gyfarfod]. PRT be-PST-1SG. in the place where-PRT be-PST-3SG M. PERF he meet 'He was in the place where Martha had met him.'

The last point that I will address in this study is what will be called the allomorph interaction problem and is typified by (4) above with the interaction of the gyda-like morphemes and the definite article. According to H\&T, OT cannot account for the correct output of the grammar because of the ill-formed phonological structures that these forms produce.

\footnotetext{
${ }^{2}$ It additionally appears to be in free variation with the yr allomorph when it appears with certain lexical items, primarily the future and past tense forms of the copula; however, an account of the free variation is beyond the scope of this study
} 
The arguments of H\&T about the inability of OT are founded if OT is understood to consist of a morpheme only having a single input and that syllabification does not occur as a result of EVAL and do pose problems to any phonological account of PCA in OT. Despite the admittedly ill-suited nature of OT in the handling of such morphophonological problems, there have been advances made to constraint-based theories in the modeling cases involving the morphology/phonology interface. One such advancement is the theory of Lexical Selection which can account for H\&T's points about to the inability of OT to account for Welsh allomorphy.

4. Lexical Selection. Lexical Selection, as a theory of the morphology/phonology interface, is concerned with how the phonological grammar can best handle the idiosyncratic nature of some allomorphs, especially when that idiosyncratic behavior is at odds with the rest of the grammar or, in other words, exceptional allomorphy (LS; Bonet et al. 2007; Mascaró 2008; Mascaró 2007; McCarvel 2016). The theory functions by restricting the role that morphology interacts with the phonology to a bare minimum. The interactions that the morphology is restricted to are the lexical listing of allomorphs, the prioritization of an allomorph or subset of allomorphs when needed, and the use of the constraint Priority to regulate the prioritization.

4.1. LEXICAL LISTING. There exists a lexical listing of all the allomorphs of a given morpheme in the input to the phonological grammar. The lexical listing of the allomorphs is necessary when there are cases of arbitrary, unmotivated instances that are not phonologically natural and when it could yield an unmarked structure. This is formalized by Mascaró (2007:718) in (8) below.

a. The set of allomorphs of a morpheme $\mathrm{M}\left(\mathrm{m}_{1}, \mathrm{~m}_{2}, \ldots, \mathrm{m}_{\mathrm{n}}\right)$ can be represented as a partially ordered set.

b. For $\mathrm{M}=/ \mathrm{m}_{1}, \mathrm{~m}_{2}, \ldots, \mathrm{m}_{\mathrm{n}} /, \operatorname{GEN}\left(/ \mathrm{m}_{1}, \mathrm{~m}_{2}, \ldots, \mathrm{m}_{\mathrm{n}} /\right)=\operatorname{GEN}\left(\mathrm{m}_{1}\right) \cup \operatorname{GEN}\left(\mathrm{m}_{2}\right) \ldots \cup$ $\operatorname{GEN}\left(\mathrm{m}_{\mathrm{n}}\right)$. (Given a set of allomorphs, the candidate set is the collection of the individual candidate sets of each allomorph.)

c. Each candidate morph in b. stands in a correspondence relation to one of the underlying allomorphs (i.e., if cand ${ }_{1} \in \mathrm{GEN}\left(/ \mathrm{m}_{\mathrm{j}} /\right.$ ), then cand $_{1} \mathfrak{R} \mathrm{m}_{\mathrm{j}}$ )

d. Under input allomorphy, candidate faithfulness violations are computed with respect to the candidate's corresponding underlying allomorph.

From this we are able to account for the variation that is observed in phonetically conditioned allomorphy. For a case in point, one can turn to a relatively simple case in the English indefinite article alan.

According to the first point, the allomorphs would be simply listed in the input as $\{\partial$, ən $\}$, in no particular order. The interaction with the constraints during EVAL will always select the correct output as can be seen in (9). Because there is no correspondence violation in either Max or Dep in regard to corresponding allomorphs in the input and output there is no need to assign violations. This is in agreement with how faithfulness constraints interact with allomorphs as outlined in (8d). The only instance of a faithfulness violation would be when there is a phonological mismatch between the corresponding allomorphs in the input and output, see (8d).

(9) OT/LS analysis of a/an allomorphy in English (Mascaró 2008:517)

a. $a[$ [ə]

\begin{tabular}{|c|c|c|c|c|}
\hline$/\{$,, ən $\}$ impossible $/$ & MAX & DEP & ONSET & NOCODA \\
\hline$\rightarrow$ a. ə.nimpossible & & & $*$ & \\
\hline b. ə.impossible & & & $* * !$ & \\
\hline
\end{tabular}


b. $\quad a[\partial]$

\begin{tabular}{|c|c|c|c|c|}
\hline$/\{$,, ən $\}$ possible $/$ & MAX & DEP & ONSET & NOCODA \\
\hline a. ə.nimpossible & & & $*$ & $* !$ \\
\hline$\rightarrow$ b. ə.impossible & & & $*$ & \\
\hline
\end{tabular}

Candidates (10.c-d), in the example below, each incur a single Ident violation as the voicing of the corresponding allomorphs in the input and output do not agree in voicing and illustrate how faithfulness violations would be assigned.

Faithfulness violations in OT/LS (Mascaró 2007:721)

\begin{tabular}{|c|c|c|c|}
\hline / ilun- $\left\{\mathrm{tu}_{1}, \mathrm{du}_{2}\right\} /$ & IDENT(voice) & *NC & *VoICEDOBST \\
\hline a. ilun- tu & & $* !$ & \\
\hline$\rightarrow$ b. ilun-du & & & * \\
\hline c. ilun-du1 & $* !$ & & $*$ \\
\hline d. ilun-tu 2 & $* !$ & * & \\
\hline
\end{tabular}

In summary, the use of allomorph sets allows for the phonology to select the correct allomorph for each of the phonological environments. These allomorphs in the input stand in direct correspondence to an allomorph in the output. Because of these correspondence relationships, allomorphs only receive faithfulness violations when there is a change in phonological structure to their correspondent. However, these allomorph sets are deficient in some respects, primarily when there is an allomorph that needs to be selected which would result in a marked phonological structure.

4.2. PRIORITIZATION. Per (9a), the listing of allomorphs can be ordered when needed. This ranking is based on the prioritization relationships between the allomorphs. The allomorphs that are prioritized are the allomorphs that do not have a specific environment that they appear in and need to be forced to appear when the conditions for the other allomorphs are not met and there is no phonological markedness constraints that forces the choice of which allomorph is allowed to surface.

This prioritization is represented in the formalism by the symbol " $>$ " and represents a dominance relation between the allomorphs or in other words a prioritization of one allomorph or a subset of allomorphs over the other allomorphs in the set. If we have a set of allomorphs $\left\{\mathrm{m}_{1}>\right.$ $\left.\mathrm{m}_{2}>\mathrm{m}_{3}\right\}$ then $\mathrm{m}_{1}$ is prioritized over $\mathrm{m}_{2}$, which in turn is prioritized over $\mathrm{m}_{3}$. However, work by Wolf (2008) shows that this use of prioritization is too powerful as there is no limit to the number of prioritization relationships. Building on Wolf, McCarvel (2016) restricts the use of these dominance relations to a single allomorph or subset of allomorphs having priority over the others which would then mean that the new set would consist of $\left\{m_{1}>m_{2}, m_{3}\right\}$ where $m_{1}$ is prioritized over both $\mathrm{m}_{2}$ and $\mathrm{m}_{3}$.

An example of how this prioritization in allomorph sets functions comes from Mascaró's (2007) discussion on the data from Baix Empordà Catalan. In this variety of Catalan, the infinitival morpheme for verbs is [-r], which assimilates to the following pronominal clitic's initial consonant but remains as $[-\mathrm{r}]$ in the presence of pronominal clitics that are vowel initial or in isolation, (11). Because of this behavior, the [-r] is given priority because its environment is unpredictable and needs to be forced when the conditions for the [ $\mathrm{n} 1 \mathrm{ts} \mathrm{m}$ ] allomorphs are not met. This prioritization is captured in (12). 
(11)

a. Nonassimilation of $[\mathrm{r}]$
pozar-u 'to put it'
pozar-i 'to put there' b. Assimilation of $[\mathrm{r}]$

$\begin{array}{ll}\text { pozam-mə } & \text { 'to put me' } \\ \text { pozas-sə } & \text { 'to put oneself' } \\ \text { pozat-tə } & \text { 'to put you' } \\ \text { pozal-ləs } & \text { 'to put them-fem' } \\ \text { pəzan-nə } & \text { 'to put some' }\end{array}$

(12) Allomorph set for the infinitival morpheme $\{\mathrm{r}>\mathrm{n}, \mathrm{l}, \mathrm{t}, \mathrm{s}, \mathrm{m}\}$

In summary, the use of prioritization within the allomorph sets allows for cases where there is an allomorph that is chosen by the grammar even if it would produce a marked phonological structure. The use of prioritization must be constrained or accounted for during the evaluation of the grammar; otherwise it would be as if there was no prioritization in the allomorph sets.

4.3. CONSTRAINT ON PRIORITIZATION. In order to account for the allomorph prioritization during EVAL, Mascaró (2007:726) introduced a faithfulness constraint PRIORITY.

\section{PRIORITY}

Respect lexical priority (ordering) of allomorphs.

"Given an input containing allomorphs $\mathrm{m}_{1}, \mathrm{~m}_{2}, \ldots, \mathrm{m}_{\mathrm{n}}$, and a candidate $\mathrm{m}_{\mathrm{i}}{ }^{\prime}$, where $\mathrm{m}_{\mathrm{i}}$ ' is in correspondence with $\mathrm{m}_{\mathrm{i}}$, PRIORITY assigns as many violation marks as the depth of ordering between $\mathrm{m}_{\mathrm{i}}$ and the highest dominating morph(s)."

However, McCarvel (2016) reformulated this constraint to be a markedness constraint based on her reinterpretation of prioritization, see (14), where there is only ever an alternation between a prioritized allomorph, or in her words a default, and non-prioritized allomorph. This reformulation can better account for the relationships of the allomorphs.

(14) PRIORITY (revised) - Assign one violation mark for use of any allomorph other than the default allomorph.

However, this redefinition is not wholly adequate for the behavior of PRIORITY as more than one allomorph can be prioritized over one or more allomorphs (see section 5.1 for a detailed discussion of such a case). Because of this fact, the definition of PRIORITY needs to be modified slighty to better reflect this.

(15) PRIORITY (adapted from Mascaró 2007 and McCarvel 2016):

Assign one violation mark for the use of any allomorph other than the prioritized allo$\operatorname{morph}(\mathrm{s})$.

In our previous example of the allomorph set $\left\{\mathrm{m}_{1}>\mathrm{m}_{2}, \mathrm{~m}_{3}\right\}$, candidate $\mathrm{m}_{1}{ }^{\prime}$ will be faithful to PRIORITY, $\mathrm{m}_{2}{ }^{\prime}$ and $\mathrm{m}_{3}{ }^{\prime}$ would both incur one violation. In returning to the Baix Empordà Catalan data. The constraint PRIORITY is required to account for the priority relationship that was explained in section 4.2. We can see that this priority relationship is correct as it allows for the allomorph [r] to surface when the conditions for the place agreement are not met. Without the constraint PRIORITY, Mascaró explains that there would be no way to allow this form to surface as any of the allomorphs satisfy the grammar when there is a clitic that is vowel-initial, as illustrated in the tableaux in (16) which are taken directly from Mascaró (2007:726). 
(16) Exceptional overassimilation in Baix Empordà Catalan. Infinitive $=/ \mathrm{s}>\mathrm{n}, 1, \mathrm{t}, \mathrm{s}, \mathrm{m} /{ }^{3}$

a. Prevocalic

\begin{tabular}{|c|c|c|c|}
\hline$/$ pozá- $\{\mathrm{c}>\mathrm{n}, \mathrm{l}, \mathrm{t}, \mathrm{s}, \mathrm{m}\}-\mathrm{u} /$ & IDENT(F) & AGREE/C & PRIORITY \\
\hline$\rightarrow$ a. puzá-f-u & & & \\
\hline b. puzá-n-u & & & $* !$ \\
\hline c. puzá-1-u & & & $* !$ \\
\hline d. puzá-t-u & & & $* !$ \\
\hline e. puzá-s-u & & & $* !$ \\
\hline f. puzá-m-u & & & $* !$ \\
\hline
\end{tabular}

b. Preconsonantal

\begin{tabular}{|c|c|c|c|}
\hline$/$ pozá- $\{\mathrm{r}>\mathrm{n}, \mathrm{l}, \mathrm{t}, \mathrm{s}, \mathrm{m}\}$-lə / & IDENT(F) & AGREE/C & PRIORITY \\
\hline a. puzá-c-lə & & $* !$ & \\
\hline$\rightarrow$ b. puzá-1-lə & & & $*$ \\
\hline
\end{tabular}

When there is a clitic beginning with a consonant than there is place agreement between the infinitival morpheme and the clitic's word initial consonant which is what the grammar in (12) correctly predicts.

In summary, LS restricts morphology to three points. These points are the use of allomorph sets, the prioritization of the allomorphs within a set, and the introduction of the constraint PRIORITY. The interaction of these points allows the phonology to select the forms needed for a given output correctly. Even though LS strongly restricts the interaction of the morphology to these three main points it nevertheless still allows us to account for all of the points that were raised by $H \& T$.

5. Welsh definite article allomorphy in OT/LS. Having now shown what LS is and the critical points behind this theory as well as how it functions within OT, we are now ideally situated to apply this theory to Welsh and the points raised by H\&T. The following analyses show that OT, with the addition of LS (OT/LS), is well suited for the task of handling the allomorphy of the DA in Welsh. In order to accomplish this, the rest of this section will be devoted to showing how each of the main points of LS can account for the each of the points of H\&T argument against OT. The first point of H\&T's argument, the grammar problem, will be analyzed in section 5.1 followed by an analysis of the homophony problem in section 5.2. Finally, an analysis of the allomorph interaction problem is given in section 5.3. It will be seen that each of the analyses are built upon one another.

5.1. THE GRAMMAR PROBLEM. The grammar problem as previously stated arises from the behavior of the definite article and the gyda-like morphemes appearing to purposely avoid instances of hiatus and codas in favor of lesser marked phonological structures, whereas the rest of the grammar does not avoid hiatus or codas (H\&T:787) as illustrated in (5) above and repeated here as (17).

(17) Examples of hiatus and codas in Welsh
a. $P\left[\begin{array}{ll}\mho \dot{\mathrm{t}} & \partial\end{array}\right] d y^{\prime} r$ meddyg
who be- PRES-IND-3SG-the doctor (hiatus across word boundaries)
'Who is the doctor.'
b. tua [ti.a]

\footnotetext{
3 There is a process in Catalan of vowel reduction that changes the unstressed vowels to [i u a ə] or [ə] depending on the variety which will not be addressed. The stress vowel is marked with an acute accent on the vowel (i.e. á).
} 
towards

'towards' (hiatus word-interanally)

c. llyfr [lit.vir]

book

'book' (coda word-finally)

d. Pwy [ə.dir] [me.ðig]

who be- PRES-IND-3SG-the doctor

'Who is the doctor?' (coda phrase-internally and word-finally)

The grammar problem is easily remedied by the incorporation of LS into OT. LS allows for each allomorph to compete in its own right during EVAL. These morphemes are then allowed to pattern idiosyncratically in respect to the rest of the grammar by having each morpheme consist of an allomorph-set in the input (see further discussion in Bonet et al. 2007; Mascaró 2007, 2008; McCarvel 2016). Additionally, during EvAL, the only instance that a faithfulness violation would occur is when there is a mismatch between the correspondence relationship between the allomorph in the input and output.

As can be seen in (18), which form of gyda/gydag is chosen by the grammar is the one that is the least marked. (18a) has gyda outputted in order to satisfy NoCODA. In (18b), we see that gydag is the output in order to satisfy HIATUS. This is in contrast to what is said by H\&T (787) in that this should produce violations in NoCODA. ${ }^{4}$ However, no additional violations in NoCODA are found with this alternation.

Correct OT output for gyda/gydag

a. Gyda in isolation or before a consonant

\begin{tabular}{|c|c|c|c|}
\hline$/\{g y d a, g y d a g\}(\mathrm{C}) /$ & FAITH & HIATUS & NOCODA \\
\hline$\rightarrow$ a. $g y \cdot d a(\mathrm{C})$ & & & \\
\hline b. $g y \cdot d a g(\mathrm{C})$ & & & $* \mathrm{~W}$ \\
\hline
\end{tabular}

b. Gydag followed by vowel-initial word

\begin{tabular}{|c|c|c|c|}
\hline$/$ \{gyda, gydag\} eraill / & FAITH & HIATUS & NOCODA \\
\hline a. gy.da.e.raill & & $* \mathrm{~W}$ & $*$ \\
\hline$\rightarrow$ b. gy.da.ge.raill & & & $*$ \\
\hline
\end{tabular}

In order to handle the definite article, we need to call on the prioritization in the allomorph sets. The use of prioritization is required to obtain the correct form during EVAL like what occured in (16a) for Baix Empordà Catalan. If we do not have the partially ordered sets in the input, the ' $r$ allomorph will not perform any better than the other allomorphs. However, this is only evident when the following word is vowel-initial. The other instances of the ' $r$ allomorph with consonant-initial words are ruled out by the phonotactics of the language which prohibits such structures (Hannahs 2013a).

(19) Inconclusive output without ordering

\begin{tabular}{|c|c|c|c|}
\hline$/\{y, y r, ' r\}$ afon $/$ & FAITH & HIATUS & NOCODA \\
\hline a. y.afon & & $* \mathrm{~W}$ & $*$ \\
\hline$\rightarrow$ b. y.ra.fon & & & $*$ \\
\hline$\rightarrow$ c. 'r.afon & & & $*$ \\
\hline
\end{tabular}

\footnotetext{
${ }^{4}$ This is due to H\&T having a different phonological analysis and acting under the assumption that syllabification is not a product of EVAL and that resyllabification does not occur across word boundaries
} 
Due to this inability to produce the correct output with simple allomorph listing, we need to use partially ordered sets. The needed form of the allomorph set has both $y$ and $y r$ being equally prioritized over ' $r$.

(20) Ordering needed for the definite article

$\{(y, y r)>r\}$

We see that this produces the correct output in (22) with $y / y r$ surfacing in every instance that is not met by the environment for ' $r$

a. $y r$ output

\begin{tabular}{|c|c|c|c|}
\hline$/\{(y, y r)>$ ' $r\}$ afon $/$ & HIATUS & PRIORITY & NOCODA \\
\hline a. y.afon & $* \mathrm{~W}$ & & $*$ \\
\hline$\rightarrow$ b. y.ra.fon & & & $*$ \\
\hline c. ra.fon & & $* \mathrm{~W}$ & $*$ \\
\hline
\end{tabular}

b.

\begin{tabular}{|c|c|c|c|}
\hline$/$ \\
\hline output \\
\hline a. o.y.afon & $* * \mathrm{~W}$ & $\mathrm{~L}$ & $*$ \\
\hline b. o.y.ra.fon & $* \mathrm{~W}$ & $\mathrm{~L}$ & $*$ \\
\hline$\rightarrow$ c. o. 'ra.fon & & $*$ & $*$ \\
\hline
\end{tabular}

According to H\&T the ' $r$ allomorph takes precedence over the other allomorphs. Because of this, one could argue that this form is the prioritized form. However, this does not produce the correct output, because the constraint Priority would require this form to be chosen over the others in every instance, (22). This is not the order that is needed, because we want $y / y r$ to surface whenever the environment for ' $r$ is not meet.

Incorrect output with $\{r>y, y r\}$
\begin{tabular}{|c|c|c|c|}
\hline$/\{r>(y, y r)\}$ afon $/$ & HIATUS & PRIORITY & NOCODA \\
\hline a. y.afon & $* \mathrm{~W}$ & & $*$ \\
\hline$(\rightarrow)$ b. y.ra.fon & & & $*$ \\
\hline$\rightarrow$ c. 'ra.fon & & $* \mathrm{~W}$ & $*$ \\
\hline
\end{tabular}

This is because the form that has precedence is only present when its conditioning is met, whereas the prioritized form is the one that is the default or non-special case. This makes precedence the exception to priority, its antithesis or the non-prioritized form and shows that precedence is not the same as prioritization.

In summary, we see that by allowing each allomorph to be present in the input through the presence of allomorph sets and allowing the prioritization of an allomorph thanks to the constraint PRIORITY we can get the output needed for our generalization correctly.

5.2. THE HOMOPHONY PROBLEM. The homophony problem is where there is a distinct homophonous morpheme with the definite article. This homophonous morpheme is a preverbal particle whose behavior and allomorphic distribution is entirely distinct from that of the definite article. ${ }^{5}$ This point can be resolved by how allomorph sets function in LS. In LS, each morpheme has its

\footnotetext{
${ }^{5}$ Following a personal conversation with David Mora Marín about this, it is possible that these two morphemes might be related and originated from the same lexeme and could be the result of the grammaticalization of a demonstrative into a definite determiner/article as well as a complementizer (which would then appear as the preverbal particle) similar to the what was observed by Talmy Givón on two homophonous morphemes in Swahili.
} 
own allomorph set. This means that the definite article and the preverbal particle each have their own distinct set, (23).

(23) Different allomorph sets for the morphemes

a. Ordering needed for the definite article $\left\{(\mathrm{y}, \mathrm{yr})>{ }^{\prime} \mathrm{r}\right\}$

b. Ordering needed for the preverbal particle ${ }^{6}$ $\{y, y r, ' r\}$

Owing to the different allomorph sets, PRIORITY will function differently for each of the sets and each set is independent from each other during EVAL.

In summary, the presence of homophonous morphemes with different allmorph distributions is not an issue for OT/LS. Each morpheme has its own unique allomorph set which functions independently during EVAL.

5.3. THE ALLOMORPH INTERACTION PROBLEM. The allomorph interaction problem is when there are interactions of $g y d a$-like morphemes and the definite article. The response to this point is a combination of the two previous responses in that it requires both allomorph listing and the use of partially ordered sets. We see this when we try to compute the phrase gyda' $r$ nod 'with the aim'. If we take the current allomorph listings for both gyda/gydag and $y / y r /$ ' $r$ we cannot produce the correct output from the grammar. This will always be the case owing to harmonic bounding of the observed form in candidate (24a) by the expected form in candidate (24b).

Invalid output with one Priority because of harmonic bounding
\begin{tabular}{|l|c|c|c|}
\hline$/\left\{g y d a\right.$, gydag $\left\{\left\{(y, y r)>{ }^{\prime} r\right\}\right.$ nod / & HIATUS & PRIORITY & NOCODA \\
\hline$(\rightarrow)$ a.gy.da'r.nod & & $* \mathrm{~W}$ & $* * \mathrm{~W}$ \\
\hline$\rightarrow$ b. gy.da.gy.nod & & & $*$ \\
\hline c. gy.da.y.nod & $* \mathrm{~W}$ & & $*$ \\
\hline d. gy.da.yr.nod & $* \mathrm{~W}$ & & $*$ \\
\hline
\end{tabular}

To resolve this issue the morpheme gyda/gydag needs to have a revised allomorph set with gyda prioritized over gydag. This prioritization is motivated by the facts of this morpheme. We explained above that the consonant-final form of this morpheme is only present when there is a vowel-initial word, in all other instances we find the vowel-final form. Because the vowel-final form appears in all other cases it receives priority over the consonant-final form.

$$
\begin{aligned}
& \text { Prioritization needed for gyda/gudag } \\
& \{\text { gyda }>\text { gydag }\}
\end{aligned}
$$

This new ranking for the morpheme gyda/gydag will be further illustrated in the following section.

5.4. PRIORITIZATION OF THE HIERARCHY. Once we make this adjustment to the allomorph set for gyda/gydag another adjustment to the theory needs to occur. Even with the addition of this new allomorph set we are still not in a position to make any progress with our analysis and the same problems that existed in (24) continue to exist in (26) and allows the phonology to be too powerful. What this means is that with a single instance of PRIORITY there is a conflicting need between the morphemes and which morpheme's priority relationship that the constraint PRIORITY is concerned with. This will continue to allow the markedness violations from

\footnotetext{
6 This is tentative and requires its own investigation.
} 
NoCODA to determine the winner and once again results in the harmonic bounding of the observed form by the expected form.

Continues incorrect output for gyda/gydag

\begin{tabular}{|l|c|c|c|}
\hline$/\{g y d a, g y d a g\}\left\{(y, y r)>{ }^{\prime} r\right\}$ nod $/$ & HIATUS & PRIORITY & NOCODA \\
\hline a. gy.da.y.nod & ${ }^{*} \mathrm{~W}$ & & $*$ \\
\hline b. gy.da.yr.nod & ${ }^{*} \mathrm{~W}$ & & $*$ \\
\hline$(\rightarrow)$ c. gy.da'r.nod & & $*$ & $* * \mathrm{~W}$ \\
\hline$\rightarrow$ d. gy.da.gy.nod & & $*$ & $*$ \\
\hline
\end{tabular}

I propose that the solution to this problem is that each morpheme has a corresponding Priority constraint in the constraint hierarchy. Multiple instances of PRIORITY allow for each morpheme and their allomorphs to interact with each other.

These multiple PRIORITY constraints appear to have a fixed or determined ranking based on whether or not one of the morpheme's phonological shape determines the phonological shape of another in what I call the Prioritization of the Hierarchy. The determining morpheme's corresponding PRIORITY constraint is ranked higher in the constraint hierarchy than the other morpheme's corresponding PRIORITY constraint.

In our example with the definite article and gyda morphemes, the gyda-like morpheme determines the phonological shape of the definite article. This means that the corresponding PRIORITY constraint for gyda is ranked higher than the corresponding definite article's PRIORITY. With this new ranking we are able to produce the correct output.

Correct output for gyda/gydag

\begin{tabular}{|c|c|c|c|c|}
\hline$/\{g y d a, g y d a g\}\left\{(y, y r)>{ }^{\prime} r\right\}$ nod $/$ & HIATUS & PRIORITY $g y d a$ & PRIORITY $y r$ & NOCODA \\
\hline a. gy.da.y.nod & ${ }^{*} \mathrm{~W}$ & & $\mathrm{~L}$ & $* \mathrm{~L}$ \\
\hline b. gy.da..yr.nod & ${ }^{*} \mathrm{~W}$ & & $\mathrm{~L}$ & $* \mathrm{~L}$ \\
\hline$\rightarrow$ c. gy.da'r.nod & & & $*$ & $* *$ \\
\hline d. gy.da.gy.nod & & ${ }^{*} \mathrm{~W}$ & $\mathrm{~L}$ & $* \mathrm{~L}$ \\
\hline
\end{tabular}

In summary, even though the interaction of multiple morphemes with each other appeared to be a problem to correctly producing the output this is overcome by having multiple allomorphs sets that each have an independent PRIORITY constraint, that is ranked according to which morpheme's final phonological shape determines the phonological shape of another morpheme. This behavior in the fixed ranking of the PRIORITY constraints is likely to be extended to other cases of multiple morpheme interaction. This requires further examination to see if the Prioritization of the Hierarchy is a universal principle or mere happenstance unique to this Welsh dataset.

6. Conclusion and further research. The analysis shown can capture the critical points of H\&T's arguments against OT, in particular, the grammar problem, the homophony problem, and the allomorph interaction problem. The strength of this analysis lies in the limiting the role of morphology to a bare minimum through the means of allomorph sets, prioritization of a single allomorph over the other allomorphs and the use of the constraint PRIORITY to allow the grammar to model that prioritization of an allomorph.

However, there are still two points that the grammar has as of yet not been able to be accounted for which are related to the discussion of the definite article and H\&T's arguments against a phonological account for the definite article. First; the phonological environment that conditions the choice of the definite article by the grammar appears to be interrupted by the presence of a prosodic boundary. 
In (28) below, the definite article is found in the environment that one would expect to see the ' $r$ allomorph in because the word yma directly precedes it. According to H\&T the lack of the ' $r$ form in this situation is the result of a prosodic boundary that interrupts or makes it impossible for the definite article to be in the correct allomorph following a vowel-final word. It appears that the environment for its conditioning is restricted to within its own phonological domain.

(28) Ni alwodd neb yma $\| \boldsymbol{y}$ dyddo'r blaen ( $\|=$ pause )

NED call-PST-3SG no-one here the day before

'No one called here the other day.'

The case of prosodic interruption could be handled merely by a constraint such as CRISPEDGE (Itô \& Mester 1999; Walker 2011) which would prevent the phonological word (in this case the definite article) from being a member of multiple phonological phrases. Another option that would prevent the definite article from interacting with other syntactic and/or prosodic items would be the constraint MATCHPHRASE (Selkirk 2009; Selkirk 2011), which prevents a prosodic phrase, and its members, from not matching isomorphically with its syntactic phrase.

The second point is the interaction of the definite article with cases of initial consonant mutation, which is a process where the initial consonant of a word will undergo various changes to this phonological form in the presence of various lexical items or prosodic/syntactic boundaries (for more information regarding initial consonant mutations the reader is referred to (Hannahs 2011; Hannahs 2013b). In Welsh, one of these lexical items is the definite article when it has a feminine singular noun as its complement in which case the initial consonant of the noun will undergo mutation.

The presence of the mutation presents issues for the analysis because the form of the definite article is conditioned on the following phonological environment. For words that have an initial $/ \mathrm{g} /$, the phone becomes null leaving potentially different phonological environments. In (29) below, the word glasog undergoes mutation becoming lasog and gardd likewise becomes ardd under mutation. These mutated lexemes then become the conditioning environments for the allomorphs of the definite article. However, these mutated lexemes are only realized when there is a definite article.
a. $y$ lasog
the gizzard.FEM.SG
b. yr ardd
the garden.FEM.SG

$$
\begin{aligned}
& \text { (glasog>lasog) } \\
& (\text { gardd }>\text { ardd })
\end{aligned}
$$

It is possible that Lexical Selection can also account for not only the interaction of the allomorphy of the definite article and initial consonant mutations but initial consonant mutations in general through the same mechanisms that allowed for the modeling of the definite article in this study.

\section{References}

Bonet, Eulàlia, Maria-Rosa Lloret \& Joan Mascaró. 2007. Allomorph selection and lexical preferences: Two case studies. Lingua 117(6). 903-927. https://doi.org/10.1016/j.lingua.2006.04.009.

Halle, Morris \& Alec Marantz. 1993. Distributed morphology and the pieces of inflection. In Kenneth Hale \& Samuel Jay Keyser (eds.), The view from building 20. 111-176. Cambridge, MA: MIT Press.

Hannahs, S. J. 2011. Celtic Mutations. The Blackwell companion to phonology. 2807-2830. Oxford: John Wiley \& Sons. https://doi.org/10.1002/9781444335262.wbctp0117.

Hannahs, S. J. 2013a. The phonology of Welsh. Oxford: Oxford University Press. 
Hannahs, S. J. 2013b. Celtic initial mutation: pattern extraction and subcategorisation. Word Structure 6(1). 1-20. https://doi.org/10.3366/word.2013.0033.

Hannahs, S. J. \& Maggie Tallerman. 2006. At the interface: selection of the Welsh definite article. Linguistics 44(4). 781-816. https://doi.org/10.1515/LING.2006.025.

Itô, Junko \& R. Armin Mester. 1999. Realignment. In Rene Kager, Harry van der Hulst \& Wim Zonneveld (eds.), The prosody-morphology interface. 188-217. Cambridge: Cambridge University Press. https://doi.org/10.1017/CBO9780511627729.007.

King, Gareth. 2015. Modern Welsh: A comprehensive grammar. Third edition. London: Routledge.

Mascaró, Joan. 2007. External allomorphy and lexical representation. Linguistic Inquiry 38(4). 715-735. https://doi.org/10.1162/ling.2007.38.4.715.

Mascaró, Joan. 2008. External allomorphy as emergence of the unmarked. In John J. McCarthy (ed.), Optimality Theory in phonology. 513-522. Oxford: Blackwell. https://doi.org/10.1002/9780470756171.ch28.

McCarvel, Miranda Kelly. 2016. Harmonic serialism with lexical selection: Evidence from Jèrriais allomorphy. University of Utah PhD Dissertation.

Prince, Alan \& Paul Smolensky. 2004. Optimality Theory. (Ed.) Alan Prince \& Paul Smolensky. Oxford, UK: Blackwell Publishing Ltd. https://doi.org/10.1002/9780470759400.

Selkirk, Elisabeth. 2009. On Clause and intonational phrase in Japanese: The syntactic grounding of prosodic constituent structure. Gengo Kenkyu 2009(136). 35-73.

Selkirk, Elisabeth. 2011. The syntax-phonology interface. The Handbook of Phonological Theory, 435-484. Oxford, UK: Wiley-Blackwell. https://doi.org/10.1002/9781444343069.ch14.

Walker, Rachel. 2011. Vowel patterns in language. Cambridge: Cambridge University Press. https://doi.org/10.1017/CBO9780511973710.

Wolf, Matthew Adam. 2008. Optimal interleaving: Serial phonology-morphology interaction in a constraint-based model. University of Massachusetts Amherst PhD Dissertation. 